\title{
Kanji Flashcards and Apps Based on Augmented Reality
}

\author{
Mukhammad S. Alfarisy ${ }^{1, *}$ Erika S. Damayanti ${ }^{1}$ Rizky Hidayah ${ }^{2}$ Nise S. Sasanti ${ }^{3}$ \\ ${ }^{1,2,3}$ Universitas Negeri Surabaya, Indonesia \\ *Corresponding author.Email: mukhammadsalman.20021@mhs.unesa.ac.id
}

\begin{abstract}
Kanji is one of the characters that must be mastered by students who are learning Japanese, apart from mastering hiragana and katakana. Based on the students' experience of difficulty in learning and memorizing kanji, flashcard is a method that can assist the memorization process. Therefore, this study intends to develop kanji flashcards and apps based on Augmented Reality (AR). AR is a technology that can insert certain information into the virtual world. This reality can be felt by the body senses through hearing, touching, and smelling. Questionnaire and documentation were used for the data collection method. This research begins with searching kanji characters such as kun-yomi, on-yomi, meaning, and number of scratches. Then, the collected data are used for card design. Later, it will be developed into a form of three-dimensional animation and projected using AR technology. The appeared animation from the AR-based card contains additional information that is not found on the physical card. It is hoped that students will find it easier and more fun to memorize kanji. This development can be a new breakthrough in technology usage in education. Based on data analysis, it is found that AR can be used as an alternative to learn kanji.
\end{abstract}

Keywords: Kanji, Flashcard, Augmented Reality (AR), Education, Technology.

\section{INTRODUCTION}

Kanji is one of the types of Japanese characters that must be memorized by students who are studying the Japanese language and literature. Kanji is a symbol that facilitates to pronounce vocabulary. However, kanji have complex forms to memorize, intricate scratches, and many of them. In fact, the Japanese people do not know exactly how many kanji there are. However, from several kanji learning applications found on Google Play Store, at least more than 2000 kanji characters are used in daily life.

Due to the obligation to memorize kanji, many students who are studying the Japanese language and literature create their own memorization method. In college, they are only asked to memorize kanji without being told an effective way. The improper memorization method causes many students to be confused and have not even reached the target kanji that must be memorized. This can be seen from a large number of students who have not reached the N5 level in the first year of study.

Based on the problems above, a solution is needed, namely changing the method of memorizing kanji from conventional to modern in order to facilitate students to memorize and write kanji. Responding to technological advances that are growing rapidly, this study offers the idea that can assist the process of memorizing kanji. The method designed is in the form of memorizing cards or commonly called flashcards. This kanji flashcard is Augmented Reality (hereafter AR)-based where the card can provide access to further information by scanning it with a particular application assisted by the user's smartphone camera. Learning through AR-based kanji flashcards is oriented towards a modern, easy, and fun learning process. In its application, this method is very suitable for any level of education who studies the Japanese language and literature in the curriculum.

\section{METHODS}

This study utilizes a descriptive-quantitative approach. In the descriptive method, the data will be described and explained systematically about the definition of kanji, its history, writing methods, how to read kanji, definition of AR, along with flashcards and apps for memorizing kanji based on AR. Meanwhile, the quantitative method was distributed to students of 
Japanese Language and Literature, Universitas Negeri Surabaya.

\section{RESULTS AND DISCUSSION}

\subsection{Definition of Kanji}

Literally, kanji (漢字) means "Han characters", which is the Chinese character used in the Japanese language. Kanji is one of the four sets of characters used in modern Japanese writing, apart from kana (katakana, hiragana) and romaji. The Japanese language has three types of character sets: hiragana, katakana, and kanji. Hiragana and katakana are phonetic symbols, i.e. each character represents the pronunciation of one syllable. Meanwhile, kanji are ideograms used to describe the meaning of each utterance. The Japanese people wrote their language with ideograms that they borrowed from Chinese nearly two thousand years ago. According to Indra in [1]-[2], two thousand years earlier, the ancient Chinese had formed ideograms from familiar images.

\subsection{History of Kanji}

Kanji appeared around $1500 \mathrm{BC}$ among the Kan tribe in China [3]. Kanji are characters that express meanings formed to imitate the shape of the object or the signs given to show the meaning of an object/nature/work/other signs. Kanji is a script system with a pictographic script as its base. The recorded number reaches more than 10,000 characters, of which 3000 characters are frequently used. With these 3000 characters, Kan words and sentences are formed. Kanji characters were created in China about 5000 years ago with a total of about 50,000 characters. However, in reality, around 2000-5000 letters are used. According to Indra in [4], kanji spread from China to Japan through North Korea about 1700 years ago.

According to some experts, kanji were formed in the Shang Dynasty in the XVI century BC. Based on the results of archaeological surveys, in the early days of the Shang Dynasty, Chinese civilization had developed to a fairly high level. It is evidenced by the appearance of Jiaguwen or characters on turtle shells and animal bones, which are characters from ancient China. According to historical records in the Shang Dynasty, the king held a divination ceremony before doing something important. Turtle shells and animal bones are tools used in divination ceremonies. Turtle shells must be processed first before being used as a medium for writing, namely by cleaning and rubbing finely. After that, the shell's top surface will be carved with neatly arranged letter marks. Normally, the soothsayer carves the name, the divination date, and the thing to be predicted. After carving, the shell will be baked so that the carving will create cracks.

\subsection{How to Write Kanji}

Kanji is made up of lines or scratches. The lines or scratches that form kanji can be counted. From this count, the number of scratches on the kanji can be seen. For example, kanji 花 (hana, flower) consists of 7 scratches. The number of lines or scratches that form a kanji is what is meant by kakusuu (画数). Lines or scratches in kanji have a writing sequence. The sequence of writing lines or scratches in kanji is called Hitsujun (筆順). The term hitsujun (sequence of writing lines/scratches) is not only used to write kanji, but is also used to write hiragana and katakana.

Lines or scratches on kanji form components of $k a n j i$. These components of a kanji are called Bushu (部 首). For instance, kanji 歩 (walk) consists of component 止 (stop) and component 少 (a little) so that 止 and 少 are bushu/ components of the kanji 歩(walk). Bushu is the most essential part of a kanji that can express the meaning of kanji in general. Bushu is also known as the basic kanji character [5]. According to Dahidi and Sudjianto [6], bushu is closely related to the parts of a $k a n j i$ character that can be used to classify kanji. For example, bushu 人 symbolizes humans, bushu 女 (women), bushu 心(heart), bushu 言 (word/language).

Japanese dictionaries published in Japan are always equipped with a bushu list to facilitate the use. The benefit of the bushu provision is that it is easy to find the meaning of a kanji in the dictionary. In addition, the existence of bushu is to facilitate the memorization of a kanji. For instance, kanji 体 (karada, body) consists of bushu イ (which symbolizes humans) and 本 (origin).

\subsection{How to Read Kanji}

Kanji is a character adopted from China. Therefore, the adoption is in the form of characters and the way of pronunciation and meaning. At that time, Japan had its own language. As a result, the existence of kanji with different pronunciations from Japanese creates a dualism in how to read characters in Japanese [5]. Therefore, almost all kanji borrowed from China have two pronunciations, namely on-yomi (音読み) which is the Chinese way of reading and kun-yomi (訓読み) which is the Japanese way of reading.

On-yomi is a way of reading kanji according to the pronunciation in ancient Chinese. According to Nandi in [7], the emergence of more than one way of reading onyomi is because changes and developments influence the kanji in China. Since the process of entering Chinese kanji comes from several periods and different places, there are three categories of pronunciation in the way of reading on, namely go-on, kan-on, and tou-on.

Kun-yomi is a way of reading kanji according to the provisions of the Japanese language. Similar to how to 
read on, how to read kun is also sometimes more than one in each kanji. This is because kanji in Japan is widely used and its use is divided into various meanings as Japanese vocabulary. As a result, the number of ways to read kun is increasing.

However, not all kanji have on-yomi and kun-yomi. Sometimes, there are kanji that have only on-yomi or vice versa. In addition, there are exceptions to the kun reading method, namely the language or vocabulary is not read from each kanji reading method but is read in a special reading way. This provision applies to the Japanese language or vocabulary that has existed since ancient times.

Kanji have a way of reading "on" and "kun". There are kanji that have only one way of reading, but there are also those with various reading ways. In general, the way of reading "on" is written in katakana characters, while "kun" is written in hiragana characters. For example, kanji (電) means electricity. This kanji only has one way of reading on-yomi, namely デン (den). On the other hand, kanji (貝) which means shellfish has one way of reading kun-yomi, namely かい(kai). Basically, kanji 貝 also has an on-yomi reading way, namely バイ (bai). Okurigana is a kana character written directly after a kanji character. It is used to determine how the kanji are read.

Furigana is kana character printed above or next to kanji to show how to read kanji. According to Kindaichi in [6], Furigana, also called yomigana or rubi, is displayed in printed characters. It can be said that furigana is a smaller kana printed next to kanji to indicate how to read kanji. Furigana used in all kanji in a text is called soorubi, while those used in certain kanji are called pararubi. According to Nomura in [6], nowadays, hiragana is often used to write furigana, but katakana has also been used to write furigana in the past.

\subsection{Definition of Augmented Reality (AR)}

$\mathrm{AR}$ is a technology that can naturally combine virtual objects (two-dimensional) and real objects (three-dimensional) through a computerized process. Both objects will be projected at the same time. Unlike Virtual Reality (VR), which places users in the virtual world completely and blocks their interactions in the real world, AR does not rule out the possibility for users to interact naturally with the real world. In AR technology, virtual objects provide various information, such as labels and virtual objects that can only be seen through input devices, such as cameras on smartphones or computers. The camera that acts as the 'eye' of AR technology will capture images and process the existing markers on an ongoing basis. Then, it will produce a virtual interaction that is visible on the real-world display both on the screen and Head-Mounted Display (HMD).

According to Sylva et al. in [8], several components are needed to support AR performance in its application. These components include:

\section{Scene generator}

A scene generator is software used for rendering. Rendering itself is the process of building a certain image or object in AR.

\section{Tracking system}

The tracking system is a component that detects virtual objects with real objects to certain patterns. The tracking system is one of the most significant components in the application of AR.

\section{Display}

There are several things that need to be considered in the display process, such as resolution quality, flexibility, point of vision, and tracking area. The lighting factor needs to be considered in the tracking area since it can affect the display process.

\section{AR device}

Not only on computers but AR can also now be applied to other devices, such as smartphones and televisions that are connected to cameras like webcams.

Kamelia [9] states that the AR system works based on markers. In simple terms, the way AR works is as follows: (1) the camera that acts as an 'eye' will detect the given marker, (2) after recognizing and marking the marker pattern, the webcam will compare it with its database. If the database matches, then the information from the marker will be used to render and display the three-dimensional object that has been created previously. Unfortunately, the marker information will not be processed if the database does not match.

According to Lyu in [8], AR has two widely used methods, as follows:

\subsubsection{Marker Based Tracking}

In this system, AR requires a marker. This marker is an image that can be analyzed to form reality. Markerbased AR uses the camera feature on the device to analyze the captured marker and then display virtual objects such as videos. Users can see all sides of virtual objects by moving the device.

\subsubsection{Markerless Augmented Reality}

In this method, users no longer need to use a marker to display virtual objects. Examples of markerless AR are face tracking, 3D object tracking, and motion 
tracking. In addition, there is also AR that utilizes GPS or digital compass features.

The history of this technology starts from 1957 to 1962, where there was a cinematographer named Morton Heilig who created a simulator called sensorama. Sensorama is a simulator that can simulate visuals, vibrations, and smells. In 1966, Ivan Shuterland invented the Head-Mounted Display (HDM), a window into the virtual world. HMD itself became the forerunner to the use of AR that uses hardware and is installed in the user's head. Head-Mounted Displays (HMD) has two main types of devices that can be used in AR applications, namely Opaque Head-Mounted Displays (Opaque HMD) and See-Through HeadMounted Displays (See-Through HMD).

In 1975, Myron Krueger, a scientist, invented a video place that allows users to interact with virtual objects. Furthermore, in 1989, Jaron Lanier introduced Virtual Reality (VR) and created the first commercial business in cyberspace. In 1992, he developed AR to make improvements to Boeing aircraft. In the same year, LB Rosenberg developed one of the functions of the AR system called Virtual Fixtures, which was used in the US Air Force "Armstrong Labs" at that time. Still, in 1992, Steven Feiner, Blair MacIntyre, and Doree Seligman introduced the first major paper to develop the first AR system prototype. In 1999, Hirokazu Kato developed "ArToolkit" in HITLab and demonstrated it at SIGGRAPH. A year later, in 2000, Bruce H. Thomas developed "ARQuake," which is an AR Mobile Game shown at the International Symposium on Wearable Computers.

Eight years later, in 2008, Wikitude AR Travel Guide introduced the Android G1 Telephone with AR technology. In 2009, Saqoosha introduced FLARToolkit, which is an extension of ArToolkit. FLARToolkit allows one to install AR technology on a page since the output produced is in the form of flash. In the same year, Wikitude Drive launched an AR navigation system on the android platform. In 2010, Acrossair used AR technology on the Iphone 3 GS.

With the advancement of technology, AR is almost used in everyday life. For example, AR is used when using a digital map (e.g. Google Maps). The system allows users to get the appropriate road route. The digital map is included in the Markerless AR method. Besides, many games use AR technology in the entertainment industry, such as Pokemon Go. Apart from games, the film industry also often uses AR to make objects look impressive. Usually, actors will shoot in front of a screen with a green or blue background which is usually referred to as a chroma key or green screen. When real imagery is combined with virtual objects, the film will look realistic as if the actor meets a real monster or is in a truly unique place.

\subsection{Kanji Flashcards and Apps Based on Augmented Reality (AR)}

This memorization card is fairly simple to make. It begins with collecting data about kanji, including kunyomi, on-yomi, number of scratches, meaning, examples, and etc. From the amount of data collected from each kanji, only six information will be listed later, namely: kanji characters, number of steps/scratches, Japanese Language Proficiency Test (JLPT) information, kun-yomi, on-yomi, and meaning. The card is printed using $310 \mathrm{gr}$ ArtPaper with glossy lamination measuring $2 \mathrm{R}(6 \mathrm{~cm} \times 9 \mathrm{~cm})$. There is also a logo from this research on the back of the card as a form of branding. The continuation of card design is to provide three-quarters of the card page with the kanji to be memorized. Along with the kanji, there is information about the number and starting point of kanji scratches in it. At the top right corner, there is Japanese Language Proficiency Test (JLPT) information. Meanwhile, at the bottom, there is a place for kun-yomi, on-yomi, and the main meaning in Indonesian.

For application creation and AR animation, a combination of two software is used, namely "unity" and "vuforia". The data obtained will be entered into various information that will look interactive and easy to use. The information begins with a moving animation of the kanji writing sequence according to the card's physically drawn. This way of writing is looping. After that, various information that is not on the card will appear, such as examples of words and sentences as well as their meanings.

This method of use is quite easy; that is, users are only asked to download and scan a memorized card with the help of a smartphone camera. After the card is scanned, the card will automatically display the animation that was previously created using the two software above. Even without being scanned, the card can still be used easily as a memorization method that has assisted students so far. However, by studying and scanning it, it is hoped that users can become more skilled at things around kanji beyond the information that is limited to physical cards.

\subsection{Questionnaire Survey of Pre-Application and Post-Application of Kanji Flashcards Based on Augmented Reality (AR)}

The questionnaire survey was carried out 2 (two) times, namely pre-application and post-application of kanji flashcards based on AR. The first questionnaire survey (pre-application of kanji flashcards based on AR) obtained 30 respondents, while the second questionnaire survey (post-application of kanji flashcards based on AR) obtained 17 respondents. 


\subsubsection{Pre-Application Questionnaire of Kanji Flashcards Based on Augmented Reality (AR)}

The questionnaire survey was carried out 2 (two) times, namely pre-application and post-application of kanji flashcards based on AR. The first questionnaire survey (pre-application of kanji flashcards based on AR) obtained 30 respondents, while the second questionnaire survey (pre-application of kanji flashcards based on AR) obtained 17 respondents.

1. Do you find it difficult to learn kanji?

"Yes $\boxminus$ Maybe $\equiv$ No

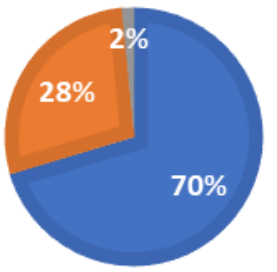

Figure 1 Difficulty in learning kanji

2. Do you find it difficult to memorize kanji?

घes $\approx$ No

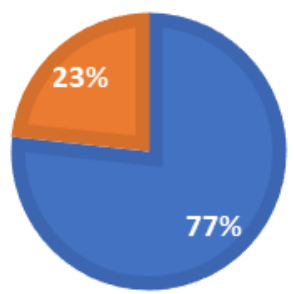

Figure 2 Difficulty in memorizing kanji

3. Does the method given by the lecturer make it easier for you to learn and memorize kanji?

$$
\text { "Yes } \backsim \text { No } \backsim \text { Maybe }
$$

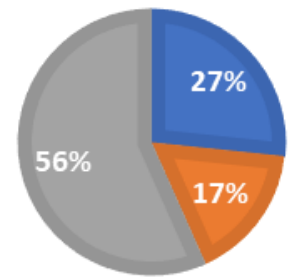

Figure 3 Ease on the method of learning and memorizing kanji

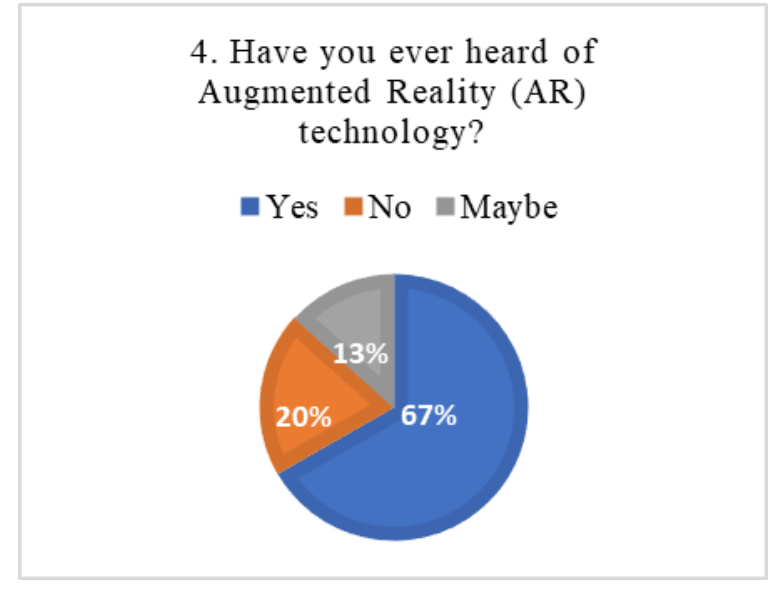

Figure 4 Knowledge about AR technology

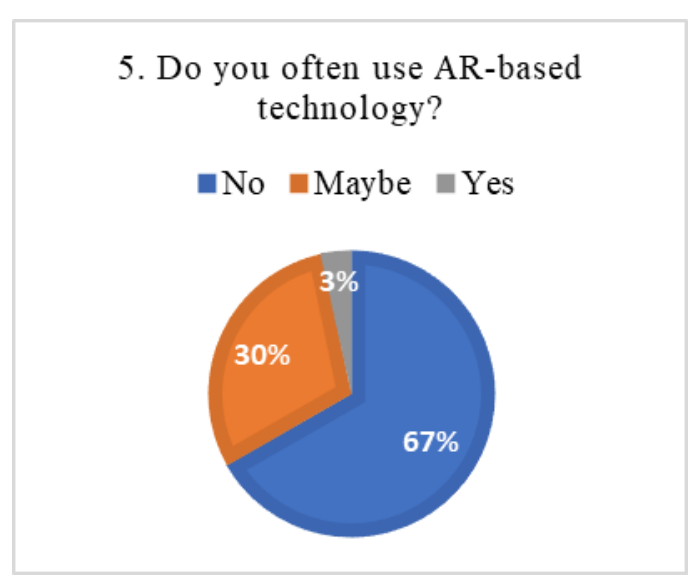

Figure 5 Frequency of using AR-based technology

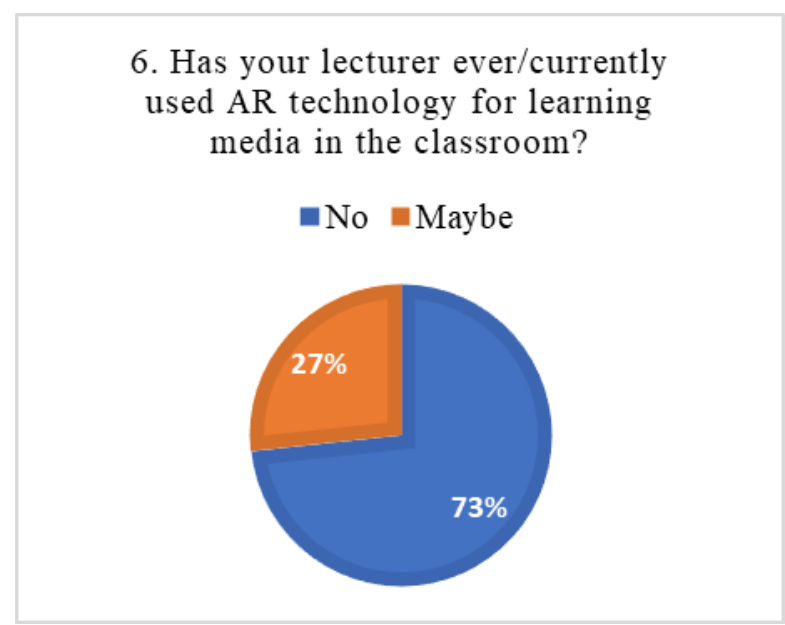

Figure 6 The use of AR technology as learning media 
7. Does kanji flashcards based on AR sound interesting to use?

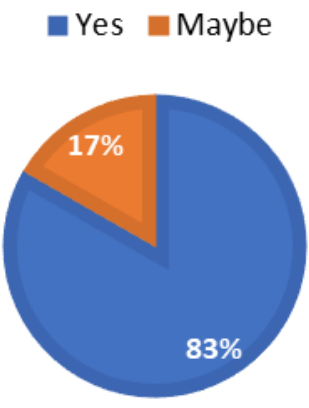

Figure 7 The interest in using kanji flashcards based on AR

\subsubsection{Post-Application Questionnaire of Kanji} Flashcards Based on Augmented Reality (AR)

1. Do you find it easy to use this learning media (kanji flashcards based on AR)?

$$
\text { - Yes Maybe }
$$

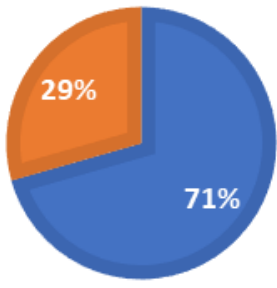

Figure 8 Ease of using kanji flashcards based on AR

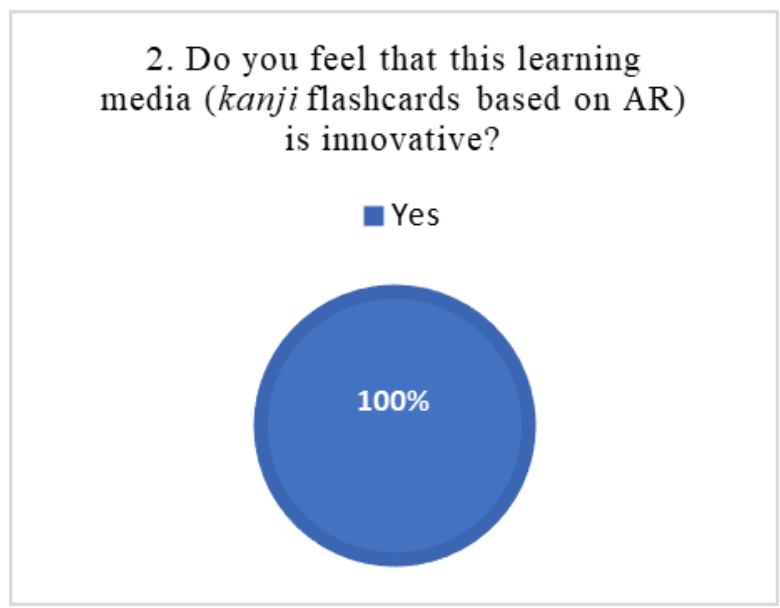

Figure 9 Perception of using kanji flashcards based on AR
3. Do you find it easy to memorize kanji using this media?

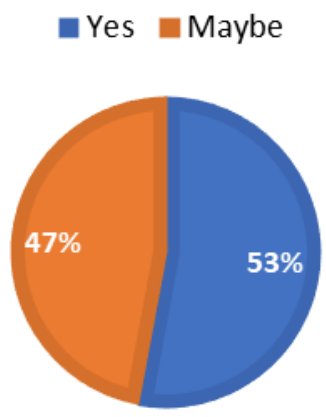

Figure 10 Ease of memorizing kanji using AR-based kanji flashcards

4. Is this media suitable to be used as learning media?

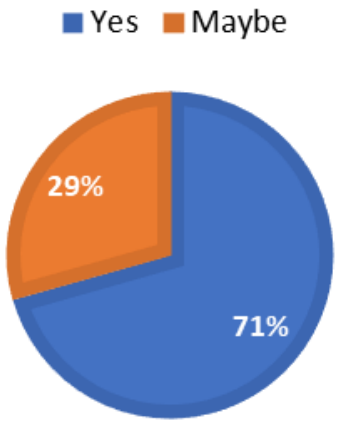

Figure 11 Suitability in the use of kanji flashcards based on AR as learning media

\section{CONCLUSION}

Japanese has 3 characters, namely hiragana, katakana, and kanji. Until now, Japanese learners still have difficulty in learning kanji. This is because the method of memorizing and learning kanji is still conventional and has not developed using technology. When learning kanji, it is known that kanji have various reading ways, there are: (1) combining on (on-yomi) and kun (kun-yomi) reading ways, (2) ways of reading with on (on-yomi) only, (3) ways of reading with kun (kunyomi) only, (4) kanji (more precisely jukugo, which is a combination of two or more kanji) which are explicitly read so that they are not read from each way of reading the kanji. This has shown that kanji is a fairly complex thing to learn. Unfortunately, the method of memorizing kanji is still conventional.

In 2021, many technologies can assist humans in their daily life. One of them is AR technology. With this technology, it is easy to combine two-dimensional and three-dimensional visuals with real situations at the same time. It is easy to feel it with our senses at a more 
complex level, such as touching, hearing, and smelling. AR technology became viral after Pokemon Go game sales boom where the user can hunt various Pokemon with movements in real-time. In addition, the use of AR technology has also been applied in various fields, such as health, industry, and of course, education.

The AR-based kanji flashcard that is developed is a new breakthrough in the education world in Indonesia, especially in the method of memorizing kanji for Japanese language learners. This flashcard will later contain information about kanji, just like flashcards already widely sold in the market. The difference is that this card will implement AR technology. When scanned through a smartphone camera with the help of a supporting application, this card will display an animation that is not found on the physical card. It includes moving animations on how to write kanji, examples of vocabulary and sentences, etc.

In this study, two questionnaire surveys were employed. Firstly, the pre-application questionnaire of kanji flashcards based on AR was used to analyze problems in memorizing kanji. It was found that the majority of respondents found it challenging to memorize kanji (66.7\%). Besides, most respondents were also interested in using AR-based kanji flashcards, with a total of 25 out of 30 respondents $(83.3 \%)$. Secondly, the post-application questionnaire of kanji flashcards based on AR was carried out. From that survey, it was found that all respondents agreed that AR-based kanji flashcards were an innovative medium to facilitate the kanji memorization method (100\%). In addition, most respondents agreed that AR-based kanji flashcards are suitable for learning media (70.6\%). Therefore, this developed media needs to be disseminated as an innovation as well as a learning media that is proven to facilitate the kanji memorization method for Japanese language learners.

\section{REFERENCES}

[1] J. Prasetyo, "Sejarah huruf Jepang," unpublished.

[2] J. Prasetyo, "Kanji no chisiki (Jukugo)," unpublished.

[3] H. Situmorang, Pengantar Linguistik Bahasa Jepang. Medan: USU Press, 2007.

[4] J. Prasetyo, "Kanji no chisiki (Yomikata)," unpublished.

[5] S. Nandi, "Pemahaman makna kanji secara praktis berdasarkan karakter dasar," Universitas Sumatera Utara, Medan, Indonesia, 2000.

[6] A. Dahidi and M. Sudjianto, Pengantar Linguistik Bahasa Jepang. Jakarta: Kesaint Blanc, 2007.
[7] T. S. Jayanto, "Analisis interpretasi makna kanji berbushu (berkarakter dasar) take kanmuri," Undergraduate Thesis. Universitas Sumatera Utara, Padang, 2010.

[8] M. R. Hanafi, “Analisis dan perancangan aplikasi geometra, media pembelajaran geometri mata pelajaran matematika berbasis android menggunakan teknologi augmented reality," Undergraduate Thesis. Universitas Negeri Yogyakarta. Yogyakarta, 2016.

[9] L. Kamelia, "Perkembangan teknologi augmented reality sebagai media pembelajaran interaktif pada mata kuliah kimia dasar," Jurnal ISTEK, vol. 9, no. 1, pp. 238-253. 2015. 